\title{
Developmental regulation of the expression of sodium currents in Xenopus primary neurons
}

\author{
PATRICIO OLGUÍN ${ }^{1}$, RICARDO ARMISEN ${ }^{2}$ and MANUEL KUKULJAN ${ }^{1}$
}

\begin{abstract}
${ }^{1}$ Programa de Fisiología y Biofísica, Instituto de Ciencias Biomédicas, Facultad de Medicina, Universidad de Chile, and Centro de Neurociencias Integradas, Iniciativa Científica Milenio

${ }^{2}$ Programa de Fisiopatología, Instituto de Ciencias Biomédicas, Facultad de Medicina, Universidad de Chile, and Howard Hughes Medical Institute, Department of Neurobiology and Behavior, State University of New York, Stony Brook
\end{abstract}

\begin{abstract}
The electrophysiological properties of neurons are determined by the expression of defined complements of ion channels. Nonetheless, the regulation mechanisms of the expression of neuronal ion channels are poorly understood, due in part to the diversity of neuron subtypes. We explored the expression of voltage-gated currents of Xenopus primary spinal neurons unequivocally identified by means of single-cell RT-PCR. We found that identified spinal neurons exhibit heterogeneity in the temporal appearance of voltage-gated currents. Nevertheless, all neurons progress to similar functional phenotypes. A physiological feature is the onset and increase of the expression of sodium currents. To understand the mechanisms underlying this process, we studied the effect of a dominant negative form of the transcriptional silencer REST/NRSF and found that it associates to an increase in the density of sodium currents. This observation is compatible with a role of this factor in the regulation of gene expression in neurons. These experiments constitute a proof of principle for the feasibility of analyzing molecular mechanisms of the regulation of ion channel genes during early neuronal development and provide direct evidence of the role of REST/NRSF in the control of neuronal sodium channel expression.
\end{abstract}

Key terms: excitability, REST/NRSF, neuronal differentiation, single-cell RT-PCR transcription.

\section{PROLOGUE}

I met Guayo and Illani in 1987, when I (MK) arrived in Santiago as a young medical graduate - all those who know them will agree that it is hard to refer to Guayo without referring to Illani and vice versa. At once, and with few recommendations on my behalf, they offered me the opportunity to help setting up a lab and running a small project, and shortly thereafter, they offered me a position at their lab at the National Institutes of Health, where I spent almost five years. These were my first glimpses of what I quickly learned to recognize as a defining feature of this couple, their unrestrained drive to support people. This generosity manifested in aspects as diverse as allowing the freedom to pursue new research with the support of their lab, welcoming whoever needed shelter at their home, helping so many to set up their laboratories around the globe, providing opportunities to start in science or always being available to listen to the problems of others, large or small (and going to impossible lengths to help solve them). Although demanding and workaholic -there was barely a Sunday without Guayo at the lab, and it was very difficult to beat him at getting in first in the morning- this demeanor taught us that hard work was just the complement for an easy laugh, a warm personal approach and for taking life in stride. 
I am thankful for the opportunity presented by this issue of Biological Research to express my deep gratitude to Guayo and Illani for their generosity and the opportunities that they have given to me and to so many others.

\section{INTRODUCTION}

Neurons' ability to generate electric signals is acquired during embryonic development, before complete morphologic differentiation and synaptic connectivity occur. The mechanisms that underlie the developmentally regulated expression of a complement of ion channels, which determine the electrophysiological properties of neurons, have not been unveiled. Similarly, the mechanisms that allow the physiological regulation of the expression of ion channels and thus of excitability in adult neurons are unknown. Underlying this incomplete understanding of the molecular regulation of excitability is the number of genes encoding ion channels found in metazoan genomes as well as the diversity of neuronal subtypes that make up nervous systems. Alternative splicing of the transcripts encoding many ion channels adds complexity to the study.

The primary nervous system of Xenopus provides a suitable vertebrate model to explore how excitability arises, as it allows the combination of physiologic and molecular approaches during early development. Additionally, the primary nervous system of Xenopus is conformed by a relatively small number of neuronal types (Hartenstein, 1989; Hartenstein, 1993). The onset of excitability was characterized in this model using classical intracellular recordings, which showed the progression from an electrically silent stage towards the state in which neurons fire rapid action potentials, passing through a condition in which "immature" action potential mainly depends on the function of calcium channels (Spitzer and Larborghini, 1976; Spitzer and Baccaglini, 1976). Patch clamp studies of cells cultured from dissociated neural plates have characterized the currents expressed in primary spinal neurons (O'Dowd et al., 1988; Desarmenien et al., 1993; Olson, 1996), and molecular correlates of some of these functional studies have been carried out, in particular regarding the characterization of potassium channels expressed in Xenopus early nervous system (i.e., Ribera, 1990; Ribera and Nguyen, 1993; Burger and Ribera, 1996; Gurantz et al., 1996; Kukuljan et al., 2003). These studies have revealed additional complexity, since apparently similar physiological features may be attained by the expression of different molecular species of potassium channels (Ribera, 1996). The molecular study of the development of the expression of neuronal sodium channels is in an incipient stage, with just the characterization of a transcript encoding a neuronal sodium channel in primary neurons (Armisén et al., 2002).

The patch clamp studies of isolated neurons have not addressed the possible heterogeneity of cell types found in neural plate cultures, and therefore, they may include a mixed population of cells, which interferes the interpretation of results. In situ recording of primary spinal neurons in Xenopus embryos, as well as in the zebrafish, provides positional information about the identity of neuron but limits the possibilities of patch clamp recording analysis (i.e., Desarmenien et al., 1993; Pineda et al., 2005); additionally, morphological differentiation of cultured neurons occurs at times in which voltage-gated currents already are expressed, and therefore, the study of these cells misses the early stages of the development of excitability (Olson, 1996). Taking this into account, we explored the possibility that cultured spinal neurons could be identified molecularly at the single-cell level before morphological differentiation and thus provide a basis for a correlation between cell identity and functional phenotype. This approach would complement the identification of ion channel genes expressed in isolated neurons (Gurantz et al., 1996). For this, we correlated the expression patterns of genes expressed in defined territories with the gene expression in cultured neurons. In the course of this study, we set out to determine if the development of the expression of voltagegated ion channels occurs in an ordered and 
synchronous manner in specific neuronal subtypes.

Regarding the transcriptional control of the expression of ion channels, there is little information involving distinct factors in this process. The transcriptional repressor REST/ NRSF was identified by its ability to silence the expression of the neuronal sodium channel gene NaV1.2 (Kraner et al., 1992; Chong et al., 1995) as well as other neuronal genes (Schoenherr and Anderson, 1995). The finding of REST/NRSF binding sequences in many neuronal and nonneuronal genes points to more extended roles than the mere control of the expression of neuronal genes (Schoenherr et al., 1996; Bruce et al., 2004), although it does not preclude its physiological role in this regard. Nevertheless, and in sharp contrast with the extensive molecular knowledge about REST/ NRSF function (i.e., Huang et al., 1999; Ballas et al., 2001; Lunyak et al., 2002; Ballas et al., 2005) these physiological roles have been studied in a limited manner, which is due in part to the apparent multiple roles of REST/NRSF during early development that determine that early loss of its functions associated with defects that preclude an analysis of adequately developed neurons (Armisén et al., 2002, Olguín et al., 2006). Recently, it has been shown that complexes set by REST/NRSF may participate not only in the control of neural development, but also in the regulation of gene expression in neurons (Ballas et al., 2005). We tested the role of REST/NRSF in neuronal sodium channel expression in Xenopus primary spinal neurons by combining the accessibility of neurons in culture with the ability to express an inducible dominant negative construct. Our results support the idea that REST/ NRSF modulates the expression of sodium channel genes in postmitotic neurons.

\section{METHODS}

\section{Embryo manipulation and microinjection}

Eggs were obtained from Xenopus laevis frogs and fertilized in vitro using standard procedures. Embryos were maintained at
$18{ }^{\circ} \mathrm{C}$ in $0.1 \mathrm{x}$ Modified Barth's Saline (MBS). Staging was done according to Nieuwkoop and Faber (1967). The RNA encoding a glucocorticoid-inducible (Kolm and Sive, 1995) dominant negative Xenopus REST/NRSF (dnXRESTi) was transcribed in vitro (Message Machine, Ambion) and microinjected into the animal pole of one blastomere at the 2-cell stage; the design of this construct is reported elsewhere (Olguín et al., 2006). GFP RNA was co-injected to verify the localization of the injected material in cell cultures.

Tissue culture, electrophysiological recording and single cell $R T-P C R$

Primary neuronal cultures were obtained by dissection of the neural plate at stages 15-16 and tissue dissociation by incubation in divalent-free saline, as described by Ribera and Spitzer (1989). Cells were plated in plastic Petri dishes, in a solution containing (in $\mathrm{mM}$ ): $116 \mathrm{NaCl}$, $0.67 \mathrm{KCl}, 1.31 \mathrm{MgSO}_{4}, 10 \mathrm{CaCl}_{2}$, 4.6 Tris, $\mathrm{pH}$ 7.8; after 4-6, 12 or 20-24 hrs in culture, cells were subject to electrophysiological recording in the whole-cell patch clamp configuration. Electrodes, with resistances within the 1.5$3 \mathrm{M} \Omega$ range were made of borosilicate capillary glass, using a P-87 horizontal puller (Sutter Instruments). For the recording of total voltage-gated currents, electrodes were filled with a solution containing (in $\mathrm{mM}$ ): $105 \mathrm{KCl}, 3 \mathrm{MgCl}_{2}, 10$ HEPES, pH 7.4. The glass electrodes were connected to the headstage of an Axopatch2A amplifier (Axon Instruments); capacitance measurements, command of voltage pulses, and acquisition were conducted using the Clampex software, part of the pClamp 8.0 suite (Axon Instruments). Single-cell RTPCR was conducted as described (Gurantz et al., 1996; Armisén et al., 2002). A nested PCR was performed with the samples obtained from each cell to determine the expression of neuronal tubulin (N-tubulin) (231 bp product). For the identification of neuronal subtypes, a multiple nested PCR was performed from $\mathrm{N}$-tubulin positives cell contents for Xlim- 
3 (281 bp) and Hox11L2 (143 bp). The following PCR primers were used; tubulin (Good et al., 1989): F1, GCCAGTGCGGTAACCAAATTG; F2, ACACGGCATTGATCCTACAG; R2, AGCTCCTTCGGTGTAATGAC; R1, T CA T GA T T C GG T C T G G G T A C TC; Hox11L2 (Patterson and Krieg, 1999): F1, GATCTTGAGCAGCTCCGACCAG; F2, CGGAGAGCTCCAGTTATTTGGG; R2, GGCAGGAGCCAGACTCACATTG; R1, CCGATGA GCTGGCACTCTAATC; XLim3 (Taira et al., 1993): F1, TTTGGGCAGACAAGCTGGAAGC; R2, CACTGCTACCGGTGGAAAGGTC; R1, GAGTGTGGTCAACCTCATCCAACC. In each case, all PCR reactions were carried out with the cDNA synthesized from the RNA obtained from each cell. PCR products were cloned (TA Cloning, Invitrogen) and sequenced for verification of the specificity of the amplification. As a control for genomic DNA contamination, a reaction with primers that amplify a fragment of XREST/NRSF, which includes an intron, was carried out (Armisén et al., 2002). Samples with genomic DNA contamination were discarded from the analysis. For the study of the role of REST/NRSF on sodium current expression, cultures were prepared from the neural plate of embryos injected with the dnXRESTi RNA and GFP RNA. After plating, dexamethasone (Sigma Chemical) $(10 \mu \mathrm{M}$, final concentration) was added to the medium. After 12 hours in culture, GFP-expressing neurons (defined by the extension of neurites) were identified by observation in an inverted epifluorescence microscope and electrophysiological recording was carried out, using an extracellular solution containing (in $\mathrm{mM}$ ): $40 \mathrm{NaCl}, 80$ TEA-Cl, $3 \mathrm{KCl}, 10 \mathrm{CoCl}_{2}, 5$ HEPES, pH 7.4; and an electrode solution containing (in $\mathrm{mM}$ ): $100 \mathrm{CsCl}, 10 \mathrm{TEA}-\mathrm{Cl}$, 10 EGTA, 10 HEPES, pH 7.4 adjusted with $\mathrm{CsOH}$. Non-fluorescent neurons from the same culture, which originated from the non-injected side and thus did not received the dominant negative REST/ NRSF RNA, were recorded and the normalized current densities were compared. The two-tailed Student's t-test was used to determine the significance of the differences measured.

\section{RESULTS AND DISCUSSION}

Xenopus primary spinal neurons display heterogeneous patterns of voltage-gated currents development

Total currents were first recorded at 4-6 hrs in culture, before typical neuronal morphological differentiation occurs. In a series of 71 cells, $53 \%$ displayed voltagegated outward currents, $17 \%$ showed both inward and outward currents, and 30\% did not expressed recordable currents (Fig. 1A). After 6-10 hours in culture, the extension of neurites allowed a clearer identification of neurons. Within this time frame, approximately $35 \%$ of the cells displayed only outward currents, $50 \%$ of the cells showed inward and outward currents, and $15 \%$ did not show measurable currents. Inward current analysis shows that $4 \%$ of cells displayed a rapidly inactivating component, while $48 \%$ of the cells displayed both the rapidly inactivating and the sustained component, presumably corresponding to voltage-dependent sodium and calcium current, respectively (Fig 1B). At $24 \mathrm{hrs}$ in culture, $67 \%$ of the cells expressed both inward and outward currents, while in $33 \%$ we detected only outward currents (Fig. 1A). Furthermore, 33\% of morphologically differentiated neurons (24 hours) displayed only the rapidly inactivating component of inward current, $62 \%$ displayed both components, and 5\% did not display ionic currents (Fig 1B). Together with the progressive increase in the number of cells expressing fast inward (sodium) currents during development, the density of these increased significantly between the 6-10 hrs and $24 \mathrm{hrs}$ in culture (data not shown). These results are consistent with the development of the ability of spinal neurons to fire action potentials (Spitzer and Lamborghini, 1976) and with previous studies on the development of the expression of voltage-gated currents 
in this system (O'Dowd et al., 1988). Nevertheless, they represent a mixed population of cells; in particular, at early stages of development in culture (4-6 hrs), the absence of defining morphological features does not allow to distinguish neurons from precursors (which had not undergone the last rounds of mitosis at the time of culture), prospective myocytes or other cell types (Olson, 1996). Therefore we proceeded to attempt to identify neurons in this mixedcell culture by conducting single-cell RT-
PCR using primers designed to amplify neuronal tubulin cDNA ( $N$-tubulin). This gene is one of the first neuronal-specific genes to be expressed in primary neurons (Chitnis et al., 1995). Table 1 shows the results of a series of cells, and Fig. 2 shows representative individual analysis. Neurons can be identified at stages in which morphological differentiation is not evident, and at later stages, there is a complete correlation between the morphological and molecular criteria for identifying neurons.

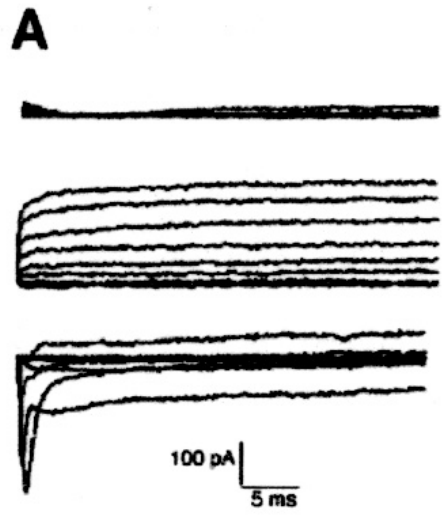

B

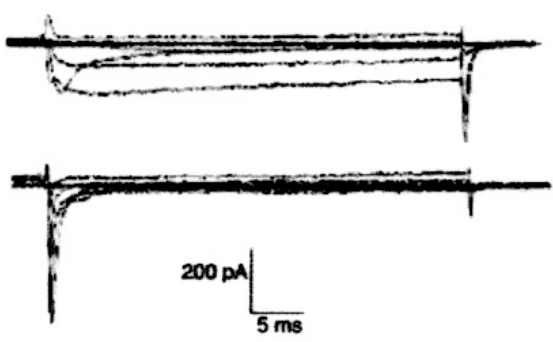

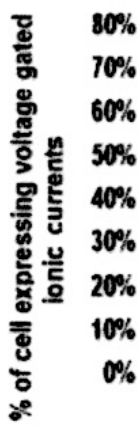
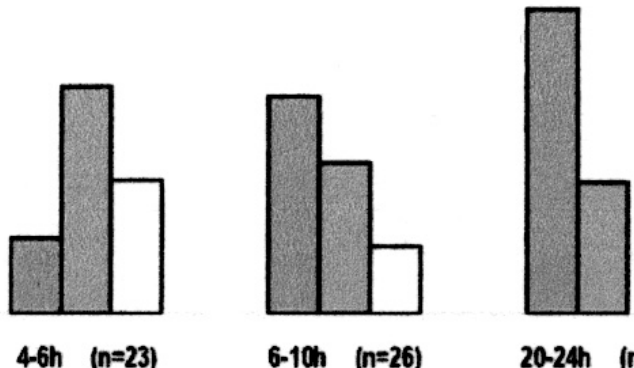

20-24h (n=12)

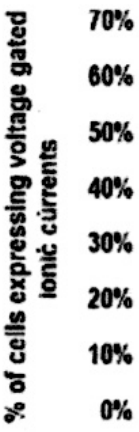

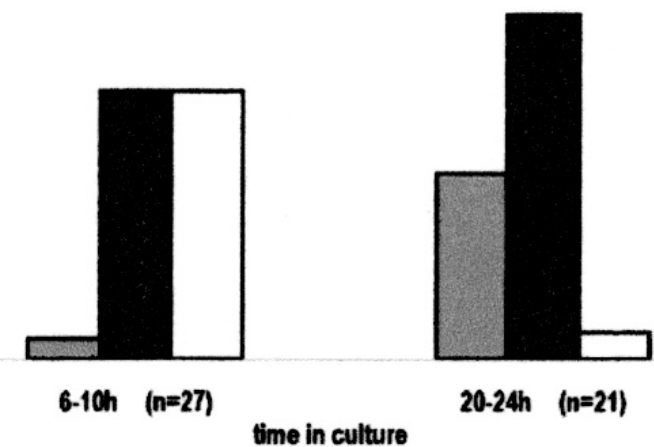

Figure 1. Acquisition of voltage-gated ionic currents during neuronal differentiation. A) Wholecell patch clamp recordings of total currents of neural plate cell cultures at different stages of development. To the left, representative electrophysiological recordings of 6-10 hours cultured cells. To the right, percentage of cells that display inward and outward currents (light gray bar), cells expressing outward currents (dark gray bar), and cells that do not display voltage-gated ionic currents (white bar). B) Analysis of voltage-dependent inward currents during development. To the left, representative electrophysiological recordings of cells at 6-10 hours in culture. To the right is the percentage of cells that express rapidly inactivating and sustained components of inward current (dark gray bar), only the rapidly inactivating component (light gray bar), and the percentage of cells that do not display inward currents (white bar). 
TABLE 1

\begin{tabular}{|c|c|c|c|c|}
\hline Hours in culture & Recorded cells & Genomic DNA + & N- $\beta$ IItubulin + & N- $\beta$ IItubulin - \\
\hline $4-6$ & $23(100 \%)$ & $7(30,4 \%)$ & $12(52,2 \%)$ & $4(17,4 \%)$ \\
\hline $6-10$ & $26(100 \%)$ & $9(34,6 \%)$ & $4(15,4 \%)$ & $13(50 \%)$ \\
\hline $20-24$ & $12(100 \%)$ & $1(8,3 \%)$ & $11(91,7 \%)$ & 0 \\
\hline
\end{tabular}

TABLE 2

\begin{tabular}{lccccc}
\hline Hours in culture & N-bIItubulin + & Hox11L2 + & Xlim-3 + & Hox11L2/XLim-3 + & Hox11L2/Xlim-3 - \\
\hline 4-6 & 12 & 2 & 3 & 1 & 6 \\
$\mathbf{6 - 1 0}$ & 4 & 1 & 0 & 2 & 1 \\
$\mathbf{2 0 - 2 4}$ & 11 & 2 & 4 & 2 & 3 \\
\hline
\end{tabular}

TABLE 3

\begin{tabular}{|c|c|c|c|c|c|c|c|c|}
\hline \multirow[b]{2}{*}{$\begin{array}{l}\text { Voltage-gated } \\
\text { current } \\
\text { Molecular } \\
\text { marker }\end{array}$} & \multicolumn{3}{|c|}{$4-6 h$} & \multicolumn{3}{|c|}{$6-10 \mathrm{~h}$} & \multicolumn{2}{|c|}{$20-24$ h } \\
\hline & Outward & $\begin{array}{l}\text { Inward/ } \\
\text { outward }\end{array}$ & None & Inward & $\begin{array}{l}\text { Inward/ } \\
\text { outward }\end{array}$ & None & Outward & $\begin{array}{r}\text { Inward/ } \\
\text { outward }\end{array}$ \\
\hline 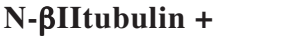 & 5 & 4 & 3 & 2 & 1 & 1 & 3 & 8 \\
\hline Hox11L2 + & 1 & 1 & 0 & 1 & 0 & 0 & 0 & 2 \\
\hline XLim-3 + & 1 & 2 & 0 & 0 & 0 & 0 & 2 & 2 \\
\hline Xlim-3/Hox11L2 + & 0 & 1 & 0 & 1 & 0 & 1 & 1 & 1 \\
\hline Xlim-3/Hox11L2 - & 3 & 0 & 3 & 0 & 1 & 0 & 0 & 3 \\
\hline
\end{tabular}

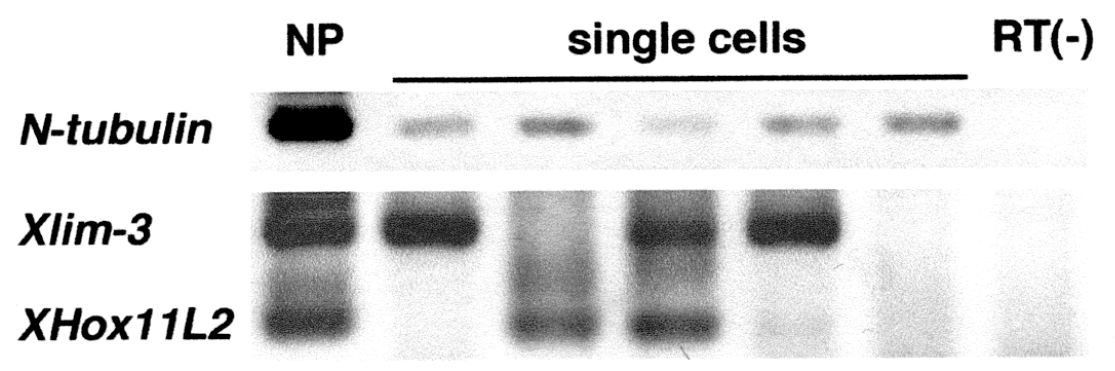

Figure 2. Representative examples of the analysis of spinal neurons identity using single-cell RTPCR. Top panel shows the analysis of N-tubulin expression of five cells cultured by 6-10 hours. Bottom panel shows the analysis of Xlim-3 and Hox11L2 expression of the corresponding cells indicated on top. NP, neural plate cDNA. RT(-) indicate reaction in which reverse transcriptase was absent. 
Using the cDNAs from which the neuronal tubulin was detected as substrates, we conducted a multiple nested PCR for Hox11L2 and Xlim3. We chose these markers as they define distinct territories in the dorsoventral axis of the neural tube (or lateromedial axis, before closure of the neural plate), being expressed in sensory neurons and motorneurons, respectively (Patterson and Krieg, 1999; Taira et al., 1993). We conducted whole mount in situ hybridization for these genes, as well as others as Pax-2, in order to verify that they express in non-overlapping territories and decided that Hox11L2 and XLim3 allowed the most unequivocal identification of distinct neuronal domains (data not shown). Primers were designed to yield products of 143 and 281 bp respectively; Table 2 shows the results of the analysis of a series of cells, and Figure 2 shows representative examples of individual cells.

We then proceeded to correlate the identity of these cells with their electrophysiological features, simply defining cells as positive for a molecular marker and describing if these cells expressed inward, outward, both, or no voltage-gated currents. This is summarized in Table 3.

Our results show that in a restricted time window and in an analysis limited to few cell subtypes, differences in the onset of expression of voltage-gated currents are apparent. This finding is compatible with an independent regulation of the expression of different ion channels, instead of a single process that commands the expression of the ensemble in each neuronal subtype. Nevertheless, the resulting functional phenotype appears as homogenous when a wider time frame is considered.

In order to gain insight into the mechanisms that govern the appearance of functional ion channels during these early stages of neuronal development, we concentrated on sodium currents. As shown above, the passage from a majority of cells either silent or expressing only outward currents to the expression of inward currents in almost all cells occurs within a time window of hours after stage 15-16. This passage correlates temporally with the transcription of xNaV1.2 (Armisén et al., 2002). Since neuronal sodium channels, particularly $\mathrm{NaV} 1.2$ and $\mathrm{NaV} 1.3$, are negatively regulated by the transcription factor REST/NRSF (Chong et al., 1995; Lunyak et al., 2002), we tested the possibility that REST/NRSF may be involved in the developmental upregulation of sodium currents. We previously demonstrated that REST/NRSF mRNA is found in spinal neurons (Armisén et al., 2002). We now studied the functional consequences of diminishing REST/NRSF in neurons by the expression of a dominant negative construct, comprising the DNA-binding domain of the transcriptional repressor. The experimental strategy allows the expression of this protein in cells derived from only one side of the embryos, recognized by the expression of the fluorescent lineage tracer GFP; the onset of the action of the dominant negative form occurs after dissociation of the neural plate, by the exposure to glucocorticoids in the culture medium (Fig 3A). Therefore, the study is restricted to neurons, recognized morphologically in vitro, which have completed the last round of mitosis. This design avoids studying cells on the background of developmental defects arising from early actions of REST/NRSF, such as the specification of ectodermal fates (Olguín et al., 2006) in Xenopus. We compared the density of current of fluorescent neurons with that recorded from non-fluorescent neurons, in which it is assumed that REST/NRSF function is normal. Figure 3B shows representative records and the summary of results obtained for a total of 27 cells, indicating that the expression of the dominant negative REST/NRSF form $(n=18)$ associates significantly $(\mathrm{p}<0.01)$ to an increase in the density of sodium currents. This observation is compatible with the idea that the transcription of neuronal sodium channel genes, at least during the earlier hours of spinal neurons, is under the control of REST/ NRSF. Therefore, its function appears as relevant not only in neuronal precursor or nonneuronal cells, but also in postmitotic neurons. This physiological result is consistent with molecular studies regarding the role of REST/NRSF in neuronal gene expression (Ballas et al., 2005). 


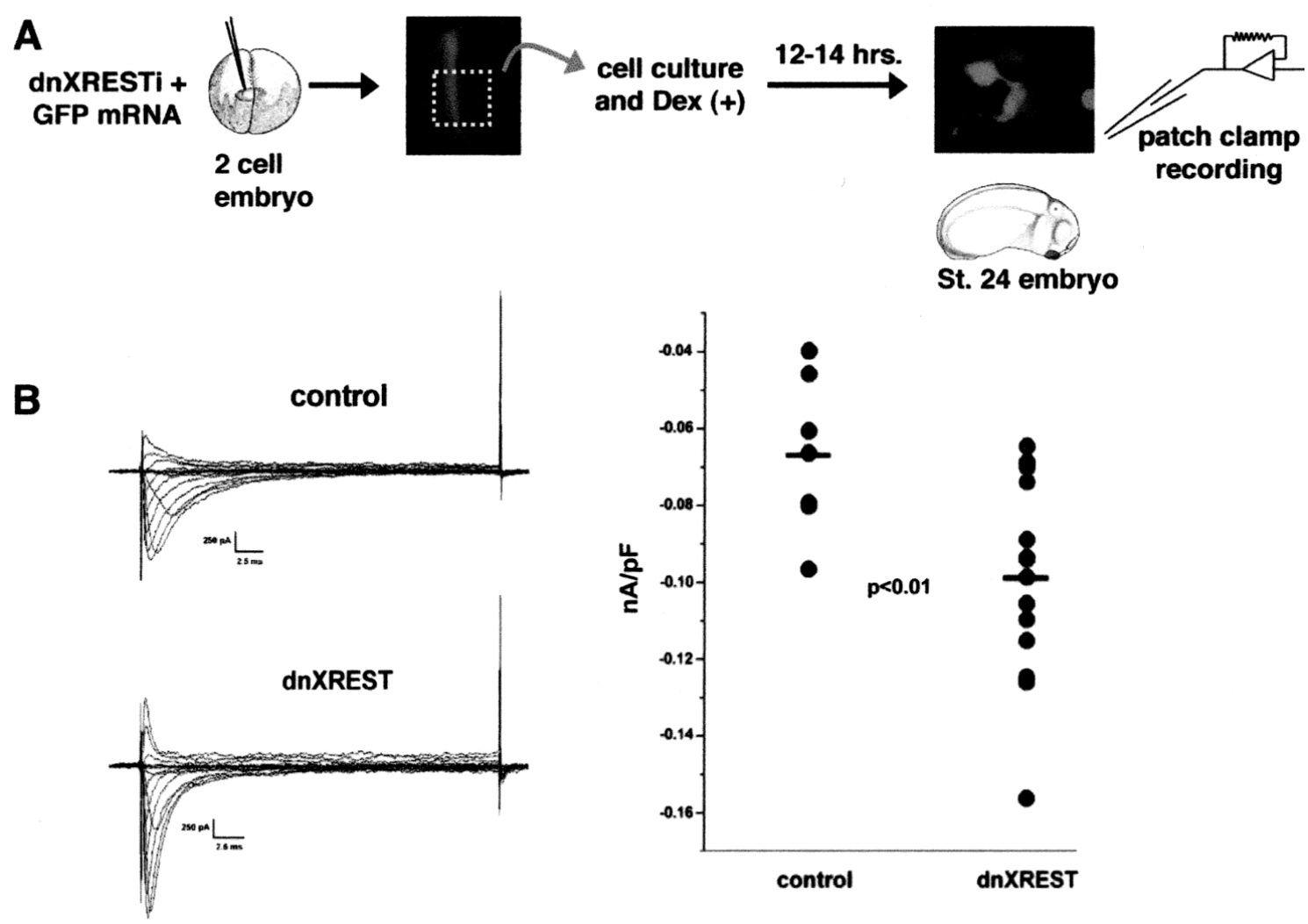

Figure 3. XREST modulates the expression of voltage-gated sodium current during neuronal differentiation. A) Experimental strategy used to knock down the activity of XREST. dnXRESTi and GFP RNA were injected in one cell of two-cell stage embryos. At midneurula stage (st. 15), the posterior half of neural plate was dissected, and cells were dissociated and cultured in the presence of dexamethasone. After 12 hours in culture (corresponding to stage 24 embryo), voltage-dependent sodium current was recorded using the whole-cell patch clamp technique. B) Analysis of sodium current density in cells with XREST loss of function (right). To the left, representative recordings of voltage-gated sodium currents: on top, control cell (non-fluorescent); bottom, dnXRESTiexpressing cell (fluorescent). The right panel shows the peak sodium current densities (measured at $-10 \mathrm{mV}$ ) of the studied series of cells.

In summary, the work presented here establishes the feasibility of studying the development of excitability in early stages of neuronal differentiation, by means of the a posteriori determination of cell identity by molecular approaches. On the other hand, it also demonstrates the possibility to selectively study the function of a transcription factor in the development of excitability and other neuronal features by combining the expression of RNA encoding inducible dominant negative forms in whole Xenopus embryos with the induction in cell cultures.

\section{ACKNOWLEDGEMENTS}

We are indebt to Dr. A.B. Ribera for her support and advice throughout this work. Supported by grant P-01-007, Iniciativa Científica Milenio; P.O. was supported by a CONICYT fellowship and predoctoral grant AT 403023.

\section{REFERENCES}

ARMISEN R, FUENTES R, OLGUÍN P, CABREJOS ME, KUKULJAN M (2002) Repressor element-1 silencing transcription/neuron-restrictive silencer factor is 
required for neural sodium channel expression during development of Xenopus. J Neurosci 22: 8347-8351

BALLAS N, BATTAGLIOLI E, ATOUF F, ANDRES ME, CHENOWETH J, ANDERSON ME, BURGER C, MONIWA M, DAVIE JR, BOWERS WJ, FEDEROFF HJ, ROSE DW, ROSENFELD MG, BREHM P, MANDEL G (2001) Regulation of neuronal traits by a novel transcriptional complex. Neuron 31: 353-365

BALLAS N, GRUNSEICH C, LU DD, SPEH JC, MANDEL G (2005) REST and its co-repressors mediate plasticity of neuronal gene chromatin throughout neurogenesis. Cell 121: 645-657

BRUCE AW, DONALDSON IJ, WOOD IC, YERBURY SA, SADOWSKI MI, CHAPMAN M, GOTTGENS B, BUCKLEY NJ (2004) Genome-wide analysis of repressor element 1 silencing transcription factor/ neuron-restrictive silencing factor (REST/NRSF) target genes. Proc Natl Acad Sci USA 101: 1045810463

BURGER C, RIBERA AB (1996) Xenopus spinal neurons express Kv2 potassium channel transcripts during embryonic development. J Neurosci 16: 1412-1421

CHITNIS A, HENRIQUE D, LEWIS J, ISH-HOROWICZ D, KINTNER C (1995) Primary neurogenesis in Xenopus embryos regulated by a homologue of the Drosophila neurogenic gene Delta. Nature 375: 761766

CHONG JA, TAPIA-RAMÍREZ J, KIM S, TOLEDOARAL JJ, ZHENG Y, BOUTROS MC, ALTSHULLER YM, FROHMAN MA, KRANER SD, MANDEL G (1995) REST: A mammalian silencer protein that restricts sodium channel gene expression to neurons. Cell 80: 949-957

DESARMENIEN MG, CLENDENING B, SPITZER NC (1993) In vivo development of voltage-dependent ionic currents in embryonic Xenopus spinal neurons. J Neurosci 13: 2575-2581

GOOD PJ, RICHTER K, DAWID IB (1989) The sequence of a nervous system-specific, class II b-tubulin gene from Xenopus laevis. Nucleic Acids Res 17: 8000

GURANTZ D, RIBERA AB, SPITZER NC (1996) Temporal regulation of Shaker- and Shab-like potassium channel gene expression in single embryonic spinal neurons during $\mathrm{K}+$ current development. J Neurosci 16: 3287-3295

HARTENSTEIN V (1989) Early neurogenesis in Xenopus: The spatio-temporal pattern of proliferation and cell lineages in the embryonic spinal cord. Neuron 3: 399411

HARTENSTEIN V (1993) Early pattern of neuronal differentiation in the Xenopus embryonic brainstem and spinal cord. J Comp Neurol 328: 213-231

HUANG Y, MYERS SJ, DINGLEDINE R (1999) Transcriptional repression by REST: Recruitment of Sin $3 \mathrm{~A}$ and histone deacetylase to neuronal genes. Nat Neurosci 2: 867-872

KOLM PJ, SIVE HL (1995) Efficient hormone-inducible protein function in Xenopus laevis. Dev Biol 171: 267 272

KUKULJAN M, TAYLOR A, CHOUINARD H, OLGUÍN P, ROJAS CV, RIBERA AB (2003) Selective regulation of xSlo splice variants during Xenopus embryogenesis. J Neurophysiol 90: 3352-3360

KRANER SD, CHONG JA, TSAY HJ, MANDEL G (1992)
Silencing the type-II sodium channel gene: A model for neural-specific gene regulation. Neuron 9: 37-44

LUNYAK VV, BURGESS R, PREFONTAINE GG, NELSON C, SZE SH, CHENOWETH J, SCHWARTZ $P$, PEVZNER PA, GLASS C, MANDEL G, ROSENFELD MG (2002) Co-repressor-dependent silencing of chromosomal regions encoding neuronal genes. Science 298: 1747-1752

NIEUWKOOP PD, FABER J (1967) Normal table of Xenopus laevis (Daudin): A sistematical and chronological survey of the development from the fertilized egg till the end of metamorphosis. 2nd Ed. Amsterdam: North Holland

ODOWD DK, RIBERA AB, SPITZER NC (1988) Development of voltage-dependent calcium, sodium, and potassium currents in Xenopus spinal neurons. J Neurosci 8: 792-805

OLGUÍN P, OTEÍZA P, GAMBOA E, GÓMEZSKARMETA JL, KUKULJAN M (2006) RE-1 silencer of transcription/neural restrictive silencer factor modulates ectodermal patterning during Xenopus development. J Neurosci 26: 2820-2829

OLSON EC (1996) Onset of electrical excitability during a period of circus plasma membrane movements in differentiating Xenopus neurons. J Neurosci 16: 5117 5129

PATTERSON KD, KRIEG PA (1999) Hox11-family genes XHox11 and XHox11L2 in Xenopus: XHox11L2 expression is restricted to a subset of the primary sensory neurons. Dev Dyn 214: 34-43

PINEDA RH, HEISER RA, RIBERA AB (2005) Developmental, molecular, and genetic dissection of INa in vivo in embryonic zebrafish sensory neurons. J Neurophysiol 93: 3582-3589

RIBERA AB (1990) A potassium channel gene is expressed at neural induction. Neuron 5: 691-701

RIBERA AB (1996) Homogeneous development of electrical excitability via heterogeneous ion channel expression. J Neurosci 16: 1123-1130

RIBERA AB, SPITZER NC (1989) A critical period of transcription required for differentiation of the action potential of spinal neurons. Neuron 2: 1055-1062

RIBERA AB, NGUYEN DA (1993) Primary sensory neurons express a Shaker-like potassium channel gene. J Neurosci 13: 4988-4996

SCHOENHERR CJ, ANDERSON DJ (1995) The neuronrestrictive silencer factor (NRSF): A coordinate repressor of multiple neuron-specific genes. Science 267: $1360-1363$

SCHOENHERR CJ, PAQUETTE AJ, ANDERSON DJ (1996) Identification of potential target genes for the neuron-restrictive silencer factor. Proc Natl Acad Sci USA 93: 9881-9886

SPITZER NC, LAMBORGHINI JE (1976) The development of the action potential mechanism of amphibian neurons isolated in culture. Proc Natl Acad Sci USA 73: 1641-1645

SPITZER NC, BACCAGLINI PI (1976) Development of the action potential in embryo amphibian neurons in vivo. Brain Res 107: 610-616

TAIRA M, HAYES WP, OTANI H, DAWID IB (1993) Expression of LIM class homeobox gene Xlim-3 in Xenopus development is limited to neural and neuroendocrine tissues. Dev Biol 159: 245-256 
